\title{
How to Write a Good Essay: General Principles for Success
}

David Stonehouse is a Lecturer in Children and Young People's Nursing with the School of Health and Society at the University of Salford, Manchester.

\begin{abstract}
.
The author has over fourteen years' experience in higher education, supporting students in essay writing and in marking across all levels up to masters, and as an external examiner. This article examines and highlights the general principles which will assist the student in writing an academic essay. Its aim is to encourage the student and to hopefully reduce some of the stress that essay writing causes. Areas such as maintaining confidentiality, word count, structure, first or third person, reflective accounts, the marking criteria, referencing, the range of robust academic sources, plagiarism, spelling and grammar and presentation will be discussed. The most important area of seeking advice from your tutor and reading feedback will be stressed.
\end{abstract}

Key Words: Academic Writing, Assistant Practitioners, Essay Writing, Nursing Associates, Students, Support Workers.

\section{Introduction}

Whether you are a Support Worker, a Assistant Practitioner, a Nursing Associate, an undergraduate nursing student, or a nurse, writing essays will likely be a part of any programme of study, or standalone modules that you undertake. Getting the basics right from the start will assist you in writing a good academic essay and will hopefully take away some of the stress that students often feel. Assessments are the process in which your tutors will determine if you have met the learning outcomes for the module of study, and have therefore passed. It is also the way in which you demonstrate your knowledge, learning and development.

\section{Maintaining Confidentiality}

This is a very important consideration and requirement for any professional programme of study. It is a clear responsibility outlined within The Code of Conduct for Healthcare Support Workers and Adult Social Care Workers in England (Skills for Care and Skills for Health, 2013). Section 5.1 states "treat all information about people who use health and care services and their carers as confidential." You must therefore never name patients, family members or carers, staff members or clinical 
areas in your writing. If you do not want to refer to your subject of discussion as the patient then you can give the patient a pseudonym, but you must make this clear in your introduction that you have done this. Often your educational institution will provide you with a standard sentence to include stating confidentiality has been maintained.

You must also guard against giving the reader any information by which they could identify the patient. So a patient with an unusual history or condition in a specific clinical area within a specialist centre could be identified by someone who knows the patient. By not maintaining confidentially will usually result in a fail grade being given by the course provider and if a registered professional this may have wider ramifications.

\section{Word Count}

Whether your assignment is 1500 words, 3000 words or 6000 words it is important that you submit your essay as close as possible to this number. The word count is not something that has just been plucked from the air. The module and programme team have decided that to answer the assignment question well it will take the recommended amount of words. If your submission is well below this magic number then there are likely to be parts which you should have included which are missing. If you are considerably over this amount, then you have possibly either repeated yourself unnecessarily or have added parts which are not relevant. Being able to write concisely and to the point is a skill to develop. Some education institutions will allow you to go $10 \%$ over or under the word count. However, if you exceed this then a penalty may be applied to your final mark. You will be required to state your word count somewhere within your essay. This will either be in a front sheet also containing your name, student number, essay title, module name and code and personal tutor name. If a front sheet is required make sure you do not forget to attach it. If the word count is not on a front sheet then state it clearly after your conclusion and before your reference list.

\section{$\underline{\text { Structure }}$}

Depending on the type of assessment will depend if a particular format is required. An assessment written as a report will have set components different to a traditional essay. However, generally speaking there should be an introduction, main body and conclusion. Your introduction should inform the reader what it is you are going to do. State what you are going to do in the order that you have discussed it within the main body.

In the main body you actually do what you have said you are going to do. This will be split up into your different paragraphs covering the required content for the assessment. Make sure your paragraphs are not too long or too short. Paragraphs should not consist of only one or two sentences. Bullet points or lists should be avoided unless clearly allowed. Always write these up in sentences and discuss 
them, or include them as appendix at the end. Appendix's do not count towards your word count.

Your conclusion then states what it is you have done. So your introduction is in the future tense and your conclusion is in the past tense. A common error that students often make is not having a clear conclusion. Their essay just stops seemingly abruptly.

\section{First or Third Person}

The general rule in academic writing is that your essay should be written in the third person. So referring to yourself as 'l' or 'me' should be avoided. Stating the author did this or the support worker or nursing associate is a good substitution. The exception is when writing a reflective account when the use of the first person is usually allowed. This should be made clear to you in the assignment guidance.

\section{$\underline{\text { Reflective Accounts }}$}

When writing a reflective essay it is important to structure your writing using a model of reflection. The assignment brief may state which model you need to use or may let you choose. One of the most commonly used models is Gibbs' Reflective Cycle (Gibbs, 1988) which has six parts, description, feelings, evaluation, analysis, conclusion and action plan. A much simpler model is Borton's Framework Model (Borton, 1970) having just three questions, What? So What? And Now What? Through the use of a model you will avoid the danger of just telling a story in your reflections, but will be able to look much deeper developing an action plan.

Reflections written for a portfolio may not always require references, but a reflective academic essay does. Students often struggle with this at first, asking 'How can I reference my own experiences?' The answer is to support your own experiences and observations with academic sources that either support or challenge what you have seen. So if you are reflecting on how you communicated with a patient, you can support this with what Sharples (2013) says about open and closed questions in communication.

\section{Marking Criteria}

The marking criteria is an important document which sets out what you need to do to gain a certain mark. It is divided into bandings usually going up in $10 \%$ 's. These bandings will be divided up into sections, usually consisting of relevant knowledge and understanding, application of theory to practice, level of analysis, level of investigations and use of supporting evidence, and finally structure, presentation and grammar. Your tutors will refer to this when they mark your essay. However it is a very good idea to look over this document before you start your essay and especially again once you have finished it. Have you met the marking criteria for a pass? Where do you think your essay sits within this grid? There will also be separate 
marking criteria for each level of study and also separate ones for each type of assessment, for example posters and group presentations.

\section{Referencing}

No matter how much we hate referencing, the fact is it really does matter and getting it right can have a huge impact on the mark you receive. Each educational institution will follow a certain referencing style and should produce a guide for you to follow. Down load or print off the guide and have it next to you to refer to as you go along.

One word of advice, do not leave completing your reference list until the very end, but do it as you go along. There is nothing worse at the end not being able to find the details of a source you have used, or trying to find which bit of paper you have the details written down on.

\section{Range of Robust Academic Sources}

It is important to use a range of different references in your writing. References taken from books, journal articles and web sites. Books are good in that due to their size they can go into much more depth on a subject than an article can. However books can often take a year or more to be written and published and the information can become out of date quite quickly. If there is more than one edition of a book always use the most up to date one. Journal articles on the other hand can be more up to date, being published quicker, but are not as big as a book, therefore may not go into as much breadth or depth in the topic. Web sites can be very good, but only if they are official sites. Sites like the World Health Organisation or The National Institute for Health and Care Excellence (NICE). Never use web sites that are aimed at members of the public giving general information and advice on a subject. You need to look at sites which are aimed at professional health care practitioners. Dictionaries should also never be used to define terms in an academic essay. Always find the term defined within an academic text.

The age of a source is important too. Generally speaking sources of up to five and ten years are acceptable. Sources older than this can be justified if they are important documents or texts. So in discussing nursing models it may be important to reference Roper, Logan and Tierney (1980), but you would be expected to use more modern references in support as well, bringing your discussion up to date.

\section{Plagiarism}

There are two types of plagiarism. One is where the student has used an author's work but has not clearly attributed it to them. This is poor referencing and poor academic writing. The other is when the student has deliberately used another person's work and are passing it off as their own. Either through copying another student's essay, or by paying for someone to write it for them. If you allow another student to copy your work then you are both guilty of plagiarism. 
Both forms are classed as plagiarism, though the second intentional type is much more serious. Both will lead to an investigation by the programme team and may lead to disciplinary and penalties being applied.

\section{Spelling and Grammar}

This is something which a lot of students struggle with. Make sure that your spell checker is switched on your computer or lap top. Also that it is set to the English spelling and not the American one which it often defaults to. Often with spellings, because we are the one who have written it, we cannot spot the mistakes by reading over our own work. Our brain thinks we have spelt it correctly. It is therefore always a good idea to ask someone to proof read your work. Though do not ask another student on your course. Friends, partners or parents who do not know the subject will be able to spot spelling and grammar errors, but will also be able to tell you if you have written it in an understandable way. A large number of spelling errors are often down to typing errors and these can be removed by proof reading.

\section{Presentation}

This really does matter. Nowadays the majority of essays will be typed and submitted electronically. This does remove the risk of handing in something which looks dog eared or crumpled, or your printer having run out of ink half way through. In the past I have seen coffee stains on essays. However you must still be careful with your typed submissions. Always use a standard font, nothing strange or fancy. Make sure the size is also not too small. Size 12 is the usual. Also make sure that both font and size do not change throughout your essay, but keep it the same throughout. Make sure your essay looks good on the page. That your reference list starts at the top of a new page and there are no gaps between paragraphs.

\section{Always Seek Guidance}

As part of the module you should have been assigned a person to go to for guidance. This will either be one of the module team or your personal tutor. I cannot stress enough the importance of you availing yourself of this valuable help. Depending on the educational institution there may be rules as to how much that person is allowed to read and give guidance on. But however much it is, I would encourage you to go. The tutor will be able to discuss your essay plan making sure that you are on the right lines and covering everything that you need to cover. If they can read some of your writing they will be able to advise on how to develop it, your content, referencing and structure, sentences and paragraphs. Tutors really do not mind. Personally I would much rather see a student before they submit and they pass, than afterwards if they have failed.

\section{Feedback}

Once your essay has been marked you will be given your mark and feedback. It is very important that you go over the feedback as this will assist you in your next 
assignment. Even if you have achieved a really good mark there is always room to improve and your feedback will tell you this. Feedback should highlight both where things could be improved and which parts were good or excellent and why.

\section{Finally}

Do not leave it to the last minute. It really does take time to gather your research, so plan time into your busy schedule so you can give it your best. If you leave it to the night before or even the week before you will not be able to seek academic guidance and will not be able to do the essay and yourself justice.

\section{Conclusion.}

So to conclude, the aim of this article has been to discuss some of the basic considerations that students need to be mindful of when writing academic essays. The aim was to allay fears around academic writing and to encourage the reader that if these basics are adhered to then they are already well on the way to success. Writing essays can be stressful, but there is help available, you just need to ask. Good luck!

\section{Key Points:}

1. Seeking guidance on your academic writing and essay is the key to success.

2. Don't leave it to the last minute or the last week.

3. Make sure you stay within the word limit, your referencing is correct and you have used a range of up to date robust academic sources.

4. Always ask someone to proof read your work before submission.

5. Don't panic, your essay is your chance to demonstrate your knowledge, learning and development.

\section{References:}

Borton T (1970) Reach, Teach and Touch. London: McGraw Hill.

Gibbs G (1988) Learning by Doing: A Guide to Teaching and Learning Methods.

Oxford: Oxford Further Education Unit.

Sharples N (2013) Relationship, helping and communication skills (193-218). In: Brooker C, Waugh A (Eds) Foundation of Nursing Practice: Fundamentals of Holistic Care. Second Edition. Mosby Elsevier: London. 
Skills for Care and Skills for Health (2013) Code of Conduct for Healthcare Support Workers and Adult Social Care Workers in England.

http://www.skillsforhealth.org.uk/images/services/code-of-

conduct/Code\%20of\%20Conduct\%20Healthcare\%20Support.pdf (accessed 2 May 2018) 